\title{
Conventional and TFPM Linear Generators for Direct-Drive Wave Energy Conversion
}

\author{
Henk Polinder, Member, IEEE, Barrie C. Mecrow, Member, IEEE, Alan G. Jack, Phillip G. Dickinson, and
} Markus A. Mueller, Member, IEEE

\begin{abstract}
The archimedes wave swing (AWS) is a system that converts ocean wave energy into electric energy. The goal of the research described in this paper is to identify the most suitable generator type for this application. Of the conventional generator types, the three-phase permanent-magnet synchronous generator with iron in both stator and translator is most suitable, because it is cheaper and more efficient than the induction generator, the switched reluctance generator, and the permanent-magnet (PM) generator with an air-gap winding. The paper also proposes a new transverse-flux PM (TFPM) generator topology that could be suitable for this application. This new double-sided moving-iron TFPM generator has flux concentrators, magnets, and conductors on the stator, while the translator only consists of iron.
\end{abstract}

Index Terms-Direct-drive generator, linear machine, permanent-magnet (PM) machine, transverse flux machine, wave energy.

\section{INTRODUCTION}

$\mathbf{W}$ AVE energy devices tend to produce low-speed reciprocating motion and extremely high forces need to be reacted. Hydraulic power take off in offshore devices and Wells' turbines in oscillating water columns (OWC) have been the favored method of interfacing a wave energy device to high-speed rotary electrical generators [1]-[3]. An alternative simpler method would be to use directly coupled linear electrical generators [4]. The Archimedes Wave Swing (AWS) is the first wave energy device to adopt direct drive power takeoff [5]-[8].

The AWS basically is an air-filled chamber, the lid of which, called the floater, can move vertically. The principle of operation is illustrated in Fig. 1. When a wave is above the AWS, its volume is reduced by the weight of the water above. When a wave trough is above the AWS, its volume increases because of the air pressure inside. From this linear motion, energy can be extracted and converted into electrical energy. In principle, this

Manuscript received April 2, 2003; revised January 8, 2004. This work was supported by the Netherlands Organization for Scientific Research (NWO). Paper no. TEC-00082-2003.

H. Polinder is with the Faculty of Electrical Engineering, Mathematics, and Computer Science, Delft University of Technology, Delft 2628 CD, The Netherlands (e-mail: h.polinder@ewi.tudelft.nl).

B. C. Mecrow and A. G. Jack are with the School of Electrical, Electronic, and Computer Engineering, University of Newcastle, Newcastle-upon-Tyne NE1 7RU, U.K. (e-mail: barrie.mecrow@ncl.ac.uk; alan.jack@ncl.ac.uk).

P. G. Dickinson is with Switched Reluctance Drives Ltd., Harrogate HG3 1PR, U.K. (e-mail: Phil.Dickinson@SRDrives.co.uk).

M. A. Mueller is with the Department of Engineering and Electronics, University of Edinburgh, Edinburgh EH9 3JL, U.K. (e-mail: markus.mueller@ ed.ac.uk).

Digital Object Identifier 10.1109/TEC.2005.845522

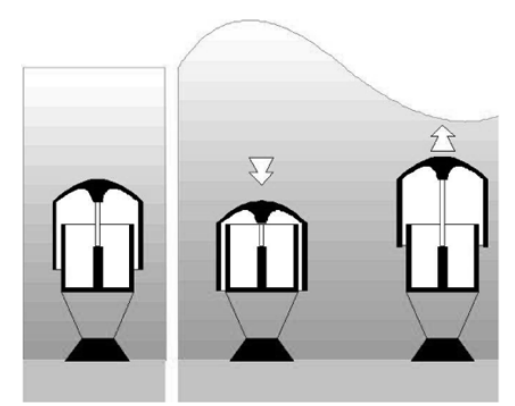

Fig. 1. Sketch of the AWS illustrating the operation principle.

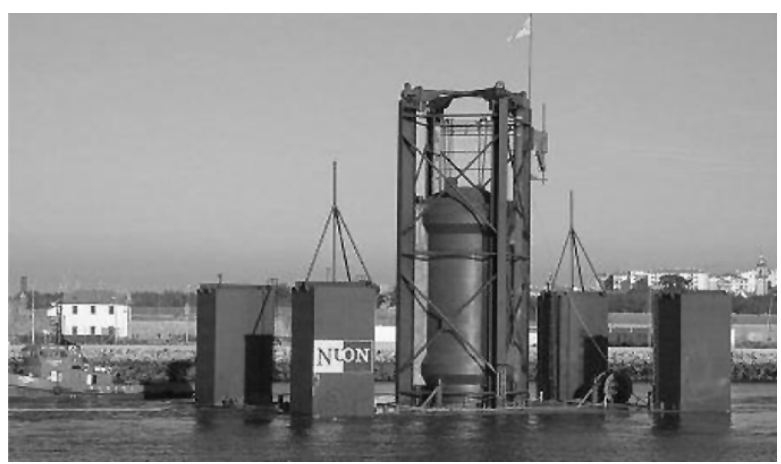

Fig. 2. Photo of the AWS pilot plant before submerging.

can be done by converting the linear motion into rotating motion and by using a rotating generator. However, it appears to be extremely difficult to build a robust, maintenance-free gear for such a conversion. Therefore, a linear generator is used, which converts the energy from the linear motion directly into electrical energy. A converter is used to connect the generator to the grid.

The pilot plant depicted in Fig. 2 has been built on a pontoon to test the complete system. The system has been submerged in September 2004. In this pilot plant, a linear permanent-magnet (PM) generator is applied. The principle of operation of the AWS, the energy yield calculations, and the generator design are described in [6] and [8]. Some generator test results are given in [7] and [8].

The linear PM generator currently applied in the AWS has a number of disadvantages.

1) The generator is very large and is, therefore, expensive. To obtain a commercially viable system, the generator should be made as cheap as possible. 
2) The attractive force between the stator and the translator (the moving part) causes big problems for the bearings, which should be made maintenance-free. Even when the generator is made double sided to balance the attractive forces (as is currently done), deviations from the ideal air gap result in severe bearing loads.

3) Losses in the generator have to be kept at an acceptable level to reduce cooling problems and increase the annual energy yield.

Therefore, the goal of the research described in this paper is to investigate electrical machine topologies for direct-drive wave energy converters.

The first part of the investigation is a review of conventional machine topologies such as PM synchronous, induction, and switched-reluctance (SR) machines. For offshore systems, low maintenance is important, so machines requiring brushes are not considered. Both iron and air-cored machines are investigated in the review, because in the latter, the impact of large electromagnetic attraction forces is less of an issue.

The conventional machine topologies listed have shear stresses in the region of $20-40 \mathrm{kN} / \mathrm{m}^{2}$, which results in very large machines for the forces to be expected from a wave energy device. Transverse flux PM machines (TFPM) are known to produce significantly higher shear stresses than conventional machine topologies [4], [9], [10]. Therefore, in the second part of this paper, a new TFPM topology is investigated and compared to the conventional machine topologies. The TFPM was not considered for the AWS pilot plant because of the difficulty in constructing the TFPM generator.

Although this paper is concerned with direct-drive wave energy conversion, it is also relevant for other applications requiring low-speed high-force linear motion. Patterson et al. [11] discuss linear synchronous machines with a comparable huge force for a completely different application with very high speeds, namely for aircraft launch systems.

\section{COMPARISON OF CONVENTIONAL GeNERATOR TyPeS}

In this section, the following five generator topologies are modeled, optimized, and compared for application in the AWS:

- induction generator without iron in the secondary;

- induction generator with iron in the secondary;

- SR generator;

- PM synchronous generator with air-gap winding;

- PM synchronous generator with stator iron.

Before this comparison, the criterion and the characteristics of the AWS are presented. The section concludes with a discussion of the results.

\section{A. Criterion for Optimization and Comparison}

The proposed criterion to compare the different generator types includes generator cost and losses

$$
C=C_{\text {gen }}+P E_{d} C_{\mathrm{kWh}}
$$

\footnotetext{
where

$C_{\text {gen }} \quad$ active generator material cost;

$P \quad$ period of five years;

$E_{d} \quad$ annual dissipation in the generator;

$C_{\mathrm{kWh}}$ price of energy.
}

When this criterion is used to optimize machine designs, it means that an additional investment in the generator efficiency must be earned back in five years.

As the basis for our calculations, we further assume:

$$
\begin{array}{ll}
\text { - } & \text { iron costs } 3 \text { Euro/kg; } \\
\text { - } & \text { copper costs } 10 \text { Euro } / \mathrm{kg} ; \\
\text { - } & \text { magnets cost } 30 \text { Euro } / \mathrm{kg} ; \\
\text { energy costs } 0.10 \mathrm{Euro} / \mathrm{kWh} .
\end{array}
$$

To evaluate this criterion, a better understanding of the AWS is necessary, which is the subject of the next section.

\section{B. Characteristics of the AWS}

The principle of operation of the AWS is discussed in [6] and [8]. Under ideal circumstances, the floater motion is sinusoidal. The rated pilot-plant floater velocity amplitude is $2.2 \mathrm{~m} / \mathrm{s}$, while the rated floater motion amplitude is $3.5 \mathrm{~m}$. The generator has to provide a damping force (a force proportional to the floater velocity), depending on the wave height and the wave period.

From the combination of force and speed, the energy extracted from a wave is calculated. The annual energy yield is calculated by combining this with the wave distribution, the annual number of waves as a function of wave height, and wave period [6], [8]. The force, the speed, and the wave distribution are also used to calculate the annual dissipation in the generator which is used in the optimization criterion (1).

To extract energy from the floater motion, the maximum force that the generator has to provide is $1 \mathrm{MN}$, which appears to be very large. However, it is approximately equal to the gravity force on $1.5 \mathrm{~m}$ of water above the 9 -m diameter floater. It is this huge force that determines the size and cost of the generator.

\section{Optimization and Assumptions}

For each generator type, a set of basic dimensions for a few pole pitches is taken. These basic dimensions are chosen so that when they are combined with the material properties and the allowed current densities and flux densities, the performance of a few pole-pitches of the machine can be calculated. The number of poles is chosen so as to generate the maximum required force, $1 \mathrm{MN}$. The optimization program varies the basic dimensions to optimize the machines to the criterion (1). In this way, roughly optimized generators are compared.

The following assumptions are used in the calculation.

- The translator is made $12 \mathrm{~m}^{2}$ larger than the stator to maintain overlap when the translator moves (as in the current generator).

- The air-gap length is $g=5 \mathrm{~mm}$ because it could not be made smaller for mechanical reasons.

- The stator slot fill factor is $k_{s}$ fil $=0.585$.

- For the induction and PM generators, the number of phases is 3 because most available converters have three phases.

- As in the current generator, the stack length is $l_{s}=$ $1 \mathrm{~m}$.

- The current density in the stator copper is limited to $5 \mathrm{~A} / \mathrm{mm}^{2}$ to prevent excessive losses.

The iron losses are usually calculated as the sum of hysteresis and eddy-current losses [12]. Here, we assume the iron losses to 
TABLE I

CHARACTERISTICS AND RESUlTS OF DIFFERENT GENERATOR TyPES

\begin{tabular}{|c|c|c|c|c|c|c|}
\hline & Generator type & $\begin{array}{r}\text { induction with iron } \\
\text { in secondary }\end{array}$ & $\begin{array}{l}\text { induction without } \\
\text { iron in secondary }\end{array}$ & $\begin{array}{r}\text { switched } \\
\text { reluctance }\end{array}$ & $\begin{array}{l}\text { PM with air- } \\
\text { gap winding }\end{array}$ & $\begin{array}{l}\text { PM with } \\
\text { stator iron }\end{array}$ \\
\hline 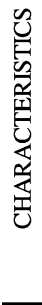 & $\begin{array}{l}\text { pole pitch } \tau_{p}(\mathrm{~mm}) \\
\text { secondary thickness } \delta_{t}(\mathrm{~mm}) \\
\text { slot height } h_{s}(\mathrm{~mm}) \\
\text { number of slots per pole per phase } \\
\text { stator slot width } b_{s}(\mathrm{~mm}) \\
\text { tooth width } b_{t}(\mathrm{~mm}) \\
\text { stator yoke height } h_{y}(\mathrm{~mm}) \\
\text { length of the magnet } l_{m}(\mathrm{~mm}) \\
\text { stator surface area } \mathrm{m}^{2} \\
\text { maximum secondary current density } J_{t}\left(\mathrm{~A} / \mathrm{mm}^{2}\right)\end{array}$ & $\begin{array}{r}324 \\
100 \\
90 \\
3 \\
18 \\
18 \\
81 \\
- \\
7.8 \\
4\end{array}$ & $\begin{array}{r}480 \\
24 \\
100 \\
4 \\
20 \\
20 \\
120 \\
- \\
10.6 \\
6\end{array}$ & $\begin{array}{r}- \\
100 \\
- \\
200 \\
100 \\
66 \\
- \\
7.2 \\
-\end{array}$ & $\begin{array}{r}100 \\
- \\
44 \\
1 \\
33 \\
- \\
25 \\
23 \\
19 \\
-\end{array}$ & $\begin{array}{r}100 \\
100 \\
1 \\
20 \\
20 \\
30 \\
15 \\
5.6 \\
-\end{array}$ \\
\hline 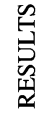 & $\begin{array}{l}\text { criterion (kEuro) } \\
\text { generator material cost (kEuro) } \\
\text { annual dissipation in the generator (MWh) } \\
\text { full load generator losses }(\mathrm{kW})\end{array}$ & $\begin{array}{l}424 \\
182 \\
483 \\
477\end{array}$ & $\begin{array}{l}745 \\
250 \\
991 \\
672\end{array}$ & $\begin{array}{l}356 \\
170 \\
373 \\
249\end{array}$ & $\begin{array}{l}434 \\
287 \\
293 \\
368\end{array}$ & $\begin{array}{l}267 \\
138 \\
260 \\
260\end{array}$ \\
\hline
\end{tabular}

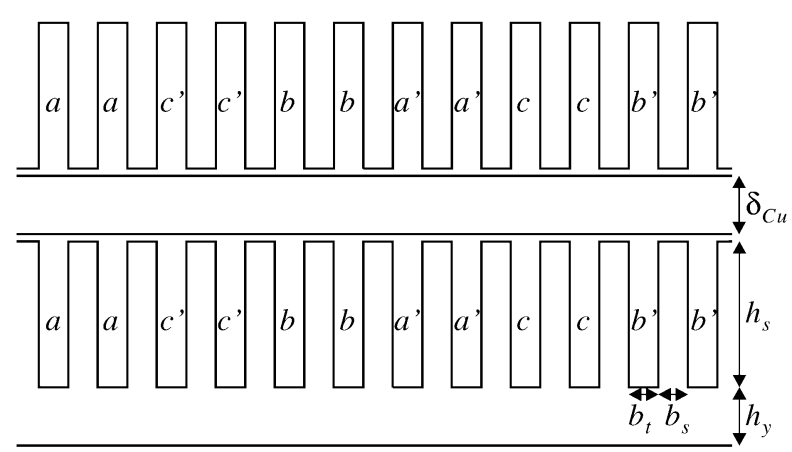

Fig. 3. Cross section of a linear induction generator.

be proportional to the frequency, which overestimates the iron losses because the frequencies are low. The stator iron losses are calculated as

$$
P_{\mathrm{Fes}}=2 P_{\mathrm{Fe}, \mathrm{spec}} M_{\mathrm{Fe}}\left(\frac{\omega_{e}}{2 \pi 50 \mathrm{~Hz}}\right)\left(\frac{\hat{B}_{\mathrm{st}}}{1.5 \mathrm{~T}}\right)^{2}
$$

where specific iron losses given by the magnetic material manufacturer are $P_{\mathrm{Fe}, \mathrm{spec}}=4.9 \mathrm{~W} / \mathrm{kg}$ at $50 \mathrm{~Hz}$ and $1.5 \mathrm{~T}$. The factor of 2 takes into account the increase of the losses due to nonsinusoidally varying fields and due to deterioration of material properties because of material handling (punching).

\section{Induction Generator Modeling}

Fig. 3 depicts a cross section of two pole pitches of a linear induction machine with some dimensions. The translator (the secondary) is placed between two stator sides. In this figure, the number of slots per pole per phase is 2 . Table I gives some important dimensions resulting from the optimization.

For the induction generator without iron in the secondary, the translator is a 24-mm-thick copper plate between a double-sided stator, so that the translator fill factor is $k_{t \text { fill }}=1$. For the induction generator with iron in the secondary, the 100-mm-thick translator consists of iron teeth and copper bars of equal width, so that the translator fill factor is $k_{t \text { fill }}=0.5$.
The amplitude of the flux density wave in the air gap of a three-phase machine without currents in the secondary is given by [12]

$$
\hat{B}_{g}=\frac{6 \mu_{0} k_{w} N_{s}}{\pi g_{\text {eff }}} \hat{i}_{\mathrm{sm}}
$$

where

$k_{w} \quad$ winding factor;

$N_{s} \quad$ number of stator turns per phase in two pole pitches per machine side;

$\hat{i}_{\text {sm }} \quad$ stator phase magnetizing current amplitude;

$g_{\text {eff }} \quad$ effective air-gap length including the secondary thickness for the induction machine without iron in the secondary, but excluding the secondary thickness for the induction machine with iron in the secondary.

It is assumed that this flux density remains constant when there is current in the secondary. In order to keep this flux density constant, it is necessary that the current in the secondary is compensated by an additional current in stator. A phase shift of $90^{\circ}$ is assumed between the stator magnetizing current and the stator current compensating the secondary current. These assumptions are too optimistic because they neglect the additional stator current necessary to compensate for leakage fields and because they neglect end effects. However, they are useful for a first approximation. With these assumptions, Faraday's law [12] can be used to calculate the current density $J_{t}$ in the secondary as

$$
J_{t}=\frac{E}{\rho_{\mathrm{Cu}}}=\frac{B_{g} \nu_{\mathrm{slip}}}{\rho_{\mathrm{Cu}}}
$$

where $\rho_{\mathrm{Cu}}$ is the resistivity of the secondary, and $\nu_{\text {slip }}$ is the velocity difference between the secondary and the air-gap flux density wave.

With the applied assumptions, the maxima of the air-gap flux density and the current density in the secondary coincide. Therefore, Lorenz force law [12] can be used to calculate the force density or shear stress as

$$
F_{d}=\frac{1}{2} \hat{B}_{g} \hat{J}_{t} \delta_{t} k_{t \text { fill }}
$$


To limit saturation in the stator, the amplitude of the air-gap flux density is limited to $0.9 \mathrm{~T}$. At low forces, flux weakening may be applied to reduce losses.

\section{E. Switched Reluctance Generator Modeling}

Fig. 4 depicts a section of a linear switched-reluctance generator. The translator is placed between two stator sides. The machine has four stator teeth per six translator teeth. This 4-6 machine doesn't function properly as a motor, but that is not necessary. The 4-6 machine is preferred to the (more common) 6-4 machine because there is more space for copper in the stator. Table I gives some important dimensions resulting from the optimization.

It is assumed that the current steps from zero to the desired value in the aligned position, and steps back to zero in the unaligned position. The flux density in the aligned position is assumed to be limited by saturation to $1.8 \mathrm{~T}$. The flux in the unaligned position is assumed to be $20 \%$ of the flux in the aligned position. The average force is then calculated using the energy conversion area of the flux linkage-current diagram [13]

$$
F=\frac{W_{\text {cycle }}}{x_{\text {cycle }}}=\frac{1}{x_{\text {cycle }}} \int_{\text {cycle }} i \mathrm{~d} \lambda
$$

where $W_{\text {cycle }}$ is the energy converted during a cycle, calculated as the area of the flux linkage-current loop, $x_{\text {cycle }}$ is the displacement during one cycle, and $\lambda$ is the flux linkage.

\section{F. Permanent-Magnet Generator Modeling}

Fig. 5 depicts a PM generator with a three-phase air-gap stator winding between two translator sides with surface-mounted magnets. Fig. 6 depicts the PM synchronous generator built for the AWS pilot plant. It has a slotted three-phase stator and a translator with surface-mounted magnets. Table I gives some important dimensions resulting from the optimization.

The fundamental of the air-gap flux density due to the magnets is calculated as

$$
B_{g}=B_{\mathrm{rm}} \frac{2 l_{m} / \mu_{\mathrm{rm}}}{2 l_{m} / \mu_{\mathrm{rm}}+g_{\mathrm{eff}}} \frac{4}{\pi} \sin \left(\frac{b_{m}}{\tau_{p}} \frac{\pi}{2}\right)
$$

where

$B_{\mathrm{rm}}$ remanent flux density of the magnets;

$l_{m} \quad$ magnet length in the direction of magnetization;

$\mu_{\mathrm{rm}}$ recoil permeability of the magnets;

$h_{s} \quad$ slot height;

$b_{m}$ magnet width;

$\tau_{p} \quad$ pole pitch;

$g_{\text {eff }}$ effective air-gap length, which is $2 g+h_{s}$ including the slot height for generator with the air-gap winding, and $2 g$ excluding the slot height for the generator with stator iron.

The force is calculated using this flux density in the expression for the Lorenz force.

\section{G. Results}

From the results summarized in Table I, it can be concluded that the PM synchronous generator with stator iron is the most suitable generator. Alternatives are all more expensive and less efficient. Besides, the magnets add to the air gap, so that devia-

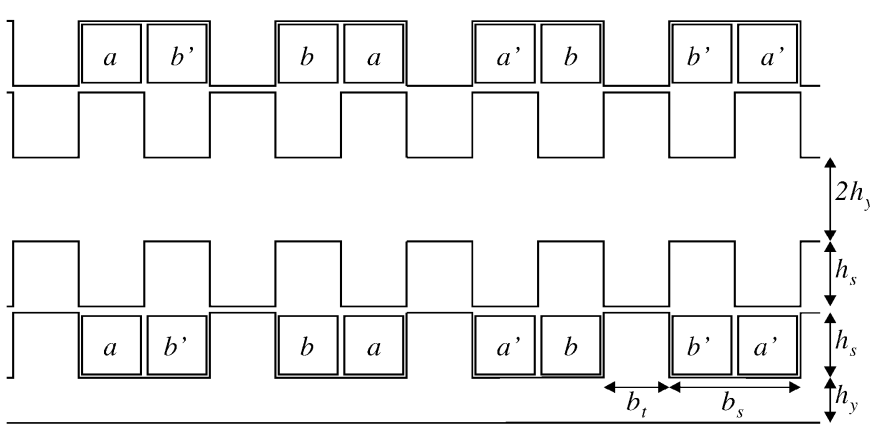

Fig. 4. Cross section of a switched reductance generator.

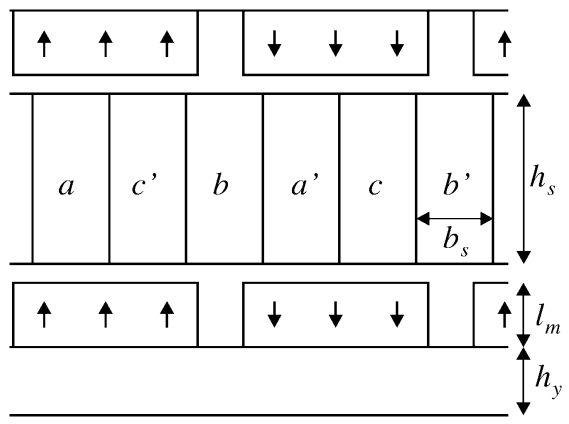

Fig. 5. Cross section of a PM synchronous generator with air-gap winding.

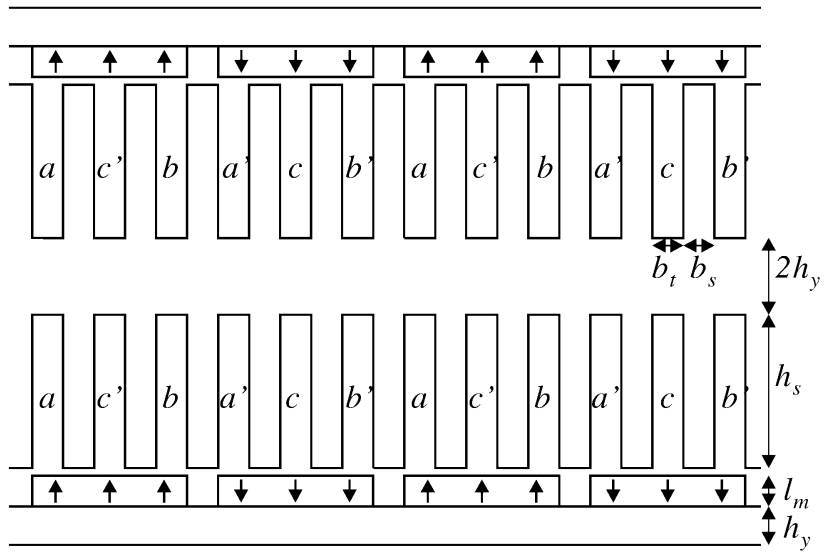

Fig. 6. Cross section of a PM synchronous generator with stator iron.

tions in the air gap result in smaller unbalanced forces than for induction machines with iron in the secondary or switched reluctance machines. The induction machine without iron in the secondary and the PM machine with air-gap winding give less bearing problems because the attractive force between stator and translator is eliminated. However, both are so much more expensive and less efficient that they are not considered to be serious alternatives for the PM synchronous generator. Probably, the large air gap and the low speed are the main reasons that induction generators give bad results.

\section{New Double-Sided Moving-IRON TFPM MACHINE}

This section starts with the introduction of a new TFPM generator topology that might be suitable for application in the 
AWS. Next, this topology is analyzed including calculations of the generated force and an estimation of the additional eddy-current losses due to three-dimensional (3-D) fields. The section ends with a discussion of the results and further work.

\section{A. New TFPM Generator Topology}

In literature, it is often claimed that TFPM machines can have much higher force densities than other machine types [4], [9], [10]. This implies that TFPM machines may be more suitable for this application than the currently applied PM synchronous machine.

TFPM machines with surface-mounted magnets tend to have a very large leakage from the poles that are not covered by U-cores into the U-cores, resulting in a disappointing performance [14]. Topologies with flux concentration generally perform better [15]-[17].

In the current generator prototype used in the AWS, the coils are in the stator and the magnets are on the translator. The translator is longer than the stator, which means that a part of the (rather expensive) magnets is not used. Therefore, it would be advantageous to have a generator topology with both the coils and the magnets in the stator and a translator consisting of only iron. Kang [18], [19] describes a TFPM topology where this is the case. The form of the coils in the double-sided TFPM machine described in [16] and [17] can also be changed in such a way that both the magnets and the coils are on the stator, while the translator consists of only iron.

These ideas form the basis for the new TFPM topology proposed here. It has been named the double-sided moving-iron TFPM because it is double-sided and the moving part consists only of iron. The easiest way to introduce this topology is to refer back to one of the original ideas of Weh [10], depicted in Fig. 7. In this topology, the stator consists of coils and U-cores on both sides of the translator, which consists of two rows of magnets and flux concentrators with space for construction material in between. To come to the new proposed topology of Fig. 8, the material between the two rows of magnets and flux concentrators is replaced by the conductors. Both the conductors and the magnets are kept stationary. The U-cores are now simpler in shape because space for coils is no longer required, and these cores or yokes form the translator.

The air gap of the TFPM generator is set to $5 \mathrm{~mm}$; the same as for the conventional generator types. The pole pitch is set to $50 \mathrm{~mm}$. If the pole pitch is increased while the number of poles is reduced to keep the total machine length the same, the flux linkage remains the same, while the frequency decreases, which results in a lower induced voltage. If the pole pitch is decreased while the number of poles is increased to keep the total machine length the same, the leakage fluxes increase so much that the induced voltage does not increase.

\section{B. FEM Analysis of Power Factor and Force}

One pole pitch of the double-sided moving-iron TFPM machine has been analyzed with FEM including saturation. Figs. 9 and 10 depict no-load results from two-dimensional (2-D) and 3-D FEM calculations.

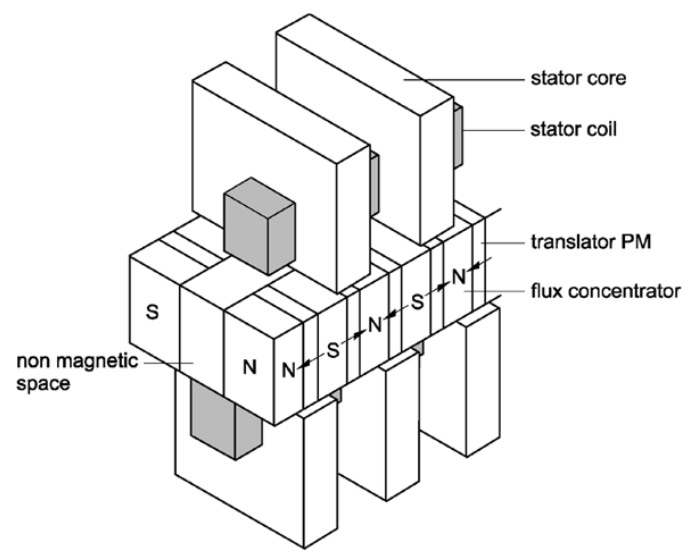

Fig. 7. TFPM machine with flux concentration and moving magnets.

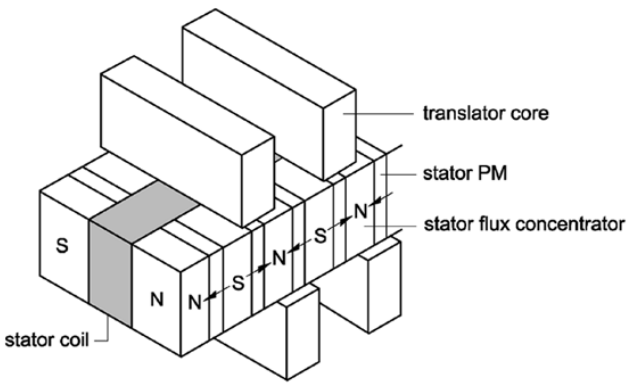

Fig. 8. TFPM machine with flux concentration and stationary magnets.

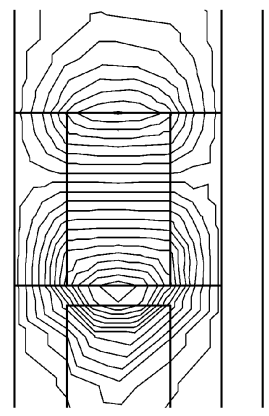

Fig. 9. Flux lines in the unaligned position resulting by 2-D FEM.

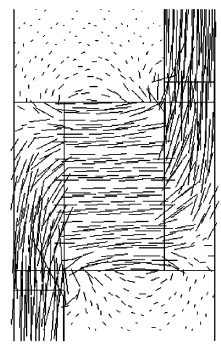

Fig. 10. Flux vectors in the aligned position resulting by 3-D FEM.

Fig. 11 depicts the magnetomotive force (mmf) of the stator current as a function of the translator position. The current is maximum in the unaligned position, which means that the current is in phase with the no-load voltage. Fig. 11 also depicts the resulting flux calculated with 3-D FEM and the derivative of the flux to the position $x$, which has the same form as the voltage if the speed is constant. This voltage is far from sinusoidal due 

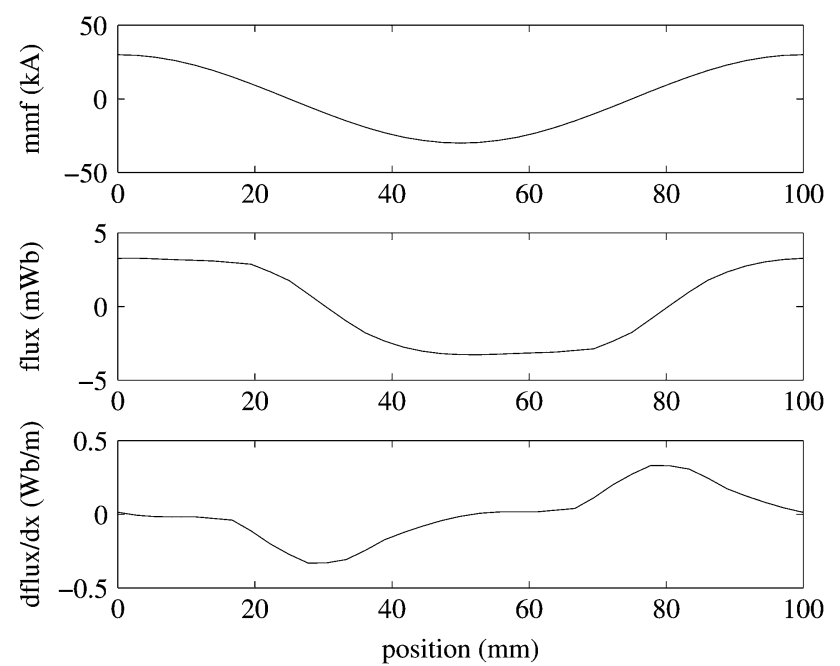

Fig. 11. Magnetomotive force, resulting flux, and the derivative of the flux to the position as a function of the position.

to heavy saturation in the translator yokes. There is space to increase the width of these yokes to reduce saturation.

From the magnetomotive force, and the derivative of the flux to the position, the power factor is calculated as 0.31 . The low power factor is a well-known disadvantage of TFPM machines, and is mainly caused by large leakage fields [4], [14]-[18].

Fig. 12 gives the flux-magnetomotive force characteristic, which encloses the same area as the flux linkage-current characteristic, so that it can be used to calculate the average force using (6), [15]-[17]. The area of this graph is $115 \mathrm{~J}$, so that 870 poles are necessary to provide a force of $1 \mathrm{MN}$.

\section{Eddy-Current Losses in the Cores}

To make the translator as simple as possible, the translator yokes should be made of laminations, where the laminations are perpendicular to the direction of the current. A disadvantage of this method of construction is that there are additional iron losses due to 3-D fields.

Figs. 9 and 10 depict the results of FEM calculations in the unaligned and the aligned position. The fields entering the translator yokes horizontally enter the laminations perpendicular to the lamination direction and cause additional eddy-current losses. According to these calculations, the maximum of the horizontal component of the flux density in the iron is between $0.7 \mathrm{~T}$ and $1 \mathrm{~T}$ depending on the permeability in the horizontal direction. Within $15 \mathrm{~mm}$, this reduces to half this value.

To obtain a first rough indication of the eddy-current losses in the iron in the translator yokes, the well-known expression for eddy-current losses per unit of volume in laminations [20] is used

$$
P_{\mathrm{Fe}}=\frac{\omega^{2} B^{2} b_{\mathrm{Fe}}^{2}}{12 \rho_{\mathrm{Fe}}}
$$

where

$\omega$ angular frequency;

$B$ flux density, uniform over the lamination width (the effect of eddy-currents on the flux density is neglected);

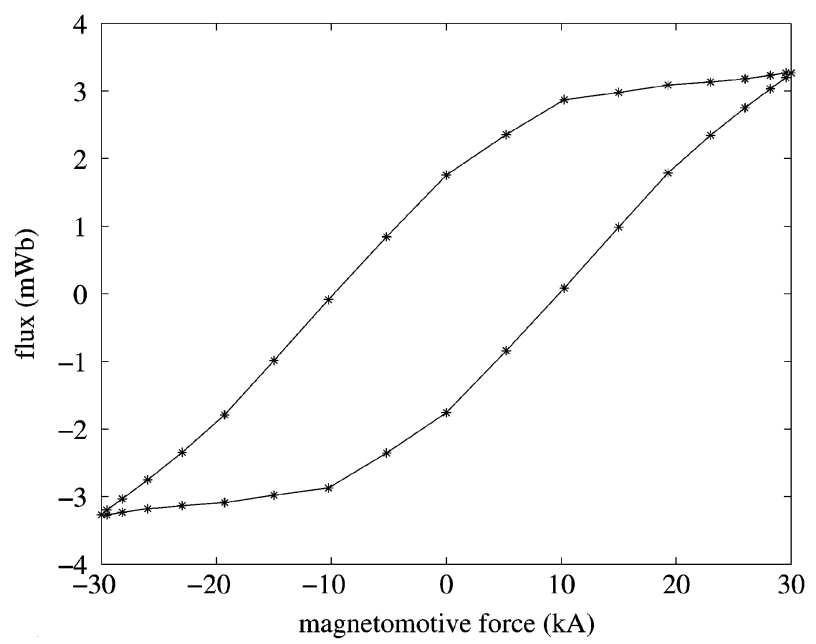

Fig. 12. Flux-magnetomotive force characteristics in the two opposite aligned positions.

$b_{\mathrm{Fe}} \quad$ width of the lamination;

$\rho_{\mathrm{Fe}}$ resistivity of the used material.

To use this equation, a number of assumptions are made.

1) The flux density entering the yoke horizontally has an amplitude of $0.5 \mathrm{~T}$ over a height of $30 \mathrm{~mm}$, so that we can use $b_{\mathrm{Fe}}=30 \mathrm{~mm}$.

2) This flux causes eddy currents in one direction over the first $15 \mathrm{~mm}$ and in the other direction over the rest of the yoke.

3) The eddy-current losses in the rest of the yoke are negligible compared to the eddy-current losses in the first $15 \mathrm{~mm}$.

4) The resistivity of iron is $\rho_{\mathrm{Fe}}=0.5 \mu \Omega \mathrm{m}$.

The resulting average additional eddy-current losses for the complete generator are $21 \mathrm{~kW}$. This is enough to worry about, because it results in an additional reduction of the annual energy yield of $184 \mathrm{MWh}$.

In order to investigate this further, finite-element method (FEM) calculations were made to determine the additional eddy-current losses in the laminations. These calculations estimated $13 \mathrm{~kW}$ of additional eddy current losses, which is still too high.

There are several ways of reducing these eddy-current losses.

1) It is possible to change the lamination direction in the lower part of a translator yoke. However, this complicates the construction considerably.

2) It is possible to use powdered iron [soft magnetic composites (SMC)] instead of laminated iron. However, this reduces eddy-current losses, but increases hysteresis losses and decreases the magnetic permeability and the saturation flux density.

3) It is possible to make narrow slots in the laminations, as proposed by Pistoyes [21], to increase the path length for the eddy currents. By making a slot with a depth of a few centimeters every centimeter, the average additional eddy-current losses should decrease by a factor of 5 to 10 to roughly $2.5 \mathrm{~kW}$. This is more acceptable and adopted in the rest of the discussion. 
TABLE II

CHARACTERISTICS OF THE DOUBLE-SIDED MOVING-IRON TFPM GENERATOR

\begin{tabular}{l|l|l|l|l}
\hline Generator type & $\begin{array}{l}\text { criterion } \\
\text { (kEuro) }\end{array}$ & $\begin{array}{l}\text { cost } \\
\text { (kEuro) }\end{array}$ & $\begin{array}{l}\text { annual dissipation in } \\
\text { the generator (MWh) }\end{array}$ & $\begin{array}{l}\text { full load } \\
\text { loss }(\mathrm{kW})\end{array}$ \\
\hline $\begin{array}{l}\text { Double-sided } \\
\text { moving-iron TFPM }\end{array}$ & 221 & 125 & 194 & 119 \\
\hline
\end{tabular}

\section{Results and Discussion}

Assuming that the average additional eddy-current losses are reduced to $2.5 \mathrm{~kW}$ by using Pistoyes slots, the results (including the additional eddy-current losses) of the analysis are summarized in Table II. The double-sided moving-iron TFPM machine appears to be only a little cheaper than the current PMSM, but considerably more efficient. A number of items need further investigation.

1) The preliminary calculations on eddy-current losses presented above have to be refined and verified.

2) The power factor is calculated as 0.31 . This means that the converter must be overrated by a factor of 3 . This is not yet a reason to stop research in this direction, because the lowspeed direct-drive generator is much more expensive than the converter, so that it might be sensible to use a more expensive converter if the generator cost can be reduced.

3) Generally, manufacturing TFPM machines is difficult. For the proposed topology, this might be worse, because the proposed stator is a rather thin and long construction, consisting of two rows of magnets and flux concentrators with conductors between these rows (Fig. 8).

4) In [15]-[17], it is shown that the use of claw-pole structures improves the performance of TFPM machines. Probably, increasing the width of the magnets and flux concentrators close to the air gap will improve the performance of the proposed topology.

These results make it worthwhile to investigate this TFPM topology further. A thorough optimization of the topology might improve the results considerably. However, after this research, we expect the improvement compared to the currently applied PM synchronous generator to be smaller than we hoped before we started this research based on references claiming large increases in force density.

\section{CONCLUSION}

Of the conventional generator types, the three-phase PM synchronous generator with iron in both stator and translator is most suitable for application in the AWS, because it is cheaper and more efficient than induction generators, switched reluctance generators and permanent-magnet generators with air-gap windings.

The new double-sided moving-iron transverse-flux permanent-magnet machine with flux concentration has both magnets and conductors in the stator, while the translator only consists of iron. Although this TFPM generator is probably difficult to build, it appears to be a little cheaper and considerably more efficient than the currently applied linear PM synchronous generator. Additional eddy-current losses in laminations due to three-dimensional fluxes can probably be limited to acceptable values by using Pistoyes slots. Therefore, it is worthwhile to investigate this topology further.

\section{REFERENCES}

[1] N. I. Meyer and K. Nielsen, "The Danish wave energy programme second year status," in Proc. 4th Wave Energy Conf., Aalborg, Denmark, 2000, pp. $10-18$.

[2] T. W. Thorpe, "The wave energy programme in the UK and the European wave energy network," in Proc. 4th Wave Energy Conf., Aalborg, Denmark, 2000, pp. 19-27.

[3] D. Scarr, "Wave Energy: Technology Transfer \& R\&D Recommendations," Rep. Ove Arup Partners International Ltd., London, U.K., 2000.

[4] M. A. Mueller, "Electrical generators for direct drive wave energy converters," in Proc. Inst. Elect. Eng., Gen., Transm. Distrib., vol. 149, 2002 , pp. $446-456$.

[5] H. Polinder, B. C. Mecrow, A. G. Jack, P. Dickinson, and M. A. Mueller, "Linear generators foir direct drive wave energy conversion," in Proc. IEEE Int. Electric Machines Drives Conf., vol. 2, Madison, WI, Jun. 2003, pp. 798-804.

[6] H. Polinder, F. Gardner, and B. Vriesema, "Linear PM generator for wave energy conversion in the AWS," in Proc. 14th Int. Conf. Electrical Machines, Helsinki, Finland, 2000, pp. 309-313.

[7] H. Polinder, M. E. C. Damen, and F. Gardner, "Modeling and test results of the AWS linear PM generator system," in Proc. 15th Int. Conf. Electrical Machines, Bruges, Belgium, 2002.

[8] — , "Linear PM generator system for wave energy conversion in the AWS," IEEE Trans. Energy Convers., vol. 19, no. 3, pp. 583-589, Sep. 2004.

[9] M. R. Dubois, H. Polinder, and J. A. Ferreira, "Comparison of generator topologies for direct-drive wind turbines," in Proc. Nordic Countries Power Industrial Electronics Conf., Aalborg, Denmark, 2000, pp. 22-26.

[10] H. Weh, H. Hoffman, and J. Landrath, "New permanent magnet excited synchronous machine with high efficiency at low speeds," in Proc. 8th Int. Conf. Electrical Machines, Pisa, Italy, 1988, pp. 35-40.

[11] D. Patterson, A. Monti, C. Brice, R. Dougal, R. Pettus, D. Srinivas, K. Dilipchandra, and T. Bertoncelli, "Design and simulation of an electromagnetic aircraft launch system," in Proc. 37th Industry Applications Annu. Meet., vol. 3, Pittsburgh, PA, 2002, pp. 1950-1957.

[12] A. E. Fitzgerald, C. Kingsley, and S. D. Umans, Electric Machinery, 6th ed. New York: McGraw-Hill, 2002.

[13] T. J. E. Miller, Switched Reluctance Motors and Their Control. Oxford, U.K.: Magna Physics Clarendon, 1993.

[14] M. R. Harris, G. H. Pajooman, and S. M. A. Sharkh, "Performance and design optimization of electric motors with heteropolar surface magnets and homopolar windings," Proc. Inst. Elect. Eng., Elect. Power Appl., vol. 143, pp. 429-436, 1996.

[15] C. P. Maddison, B. C. Mecrow, and A. G. Jack, "Claw pole geometries for high performance transverse flux machines," in Proc. 13th Int. Conf. Electrical Machines, Istanbul, Turkey, 1998, pp. 340-345.

[16] B. C. Mecrow, A. G. Jack, and C. P. Maddison, "Permanent magnet machines for high torque, low speed applications," in Proc. 12th Int. Conf. Electrical Machines, Vigo, Spain, 1996, pp. 461-466.

[17] C. P. Maddison, "Transverse flux machines for high torque applications," Ph.D. dissertation, Univ. Newcastle-upon-Tyne, U.K., 1999.

[18] D. H. Kang, "Transversalflussmaschinen met permanenter erregung als linearantriebe im schienengebundenen verkehr," Ph.D. dissertation, Techn. Univ. Carolo-Wilhelmina, Braunschweig, Germany, 1996.

[19] D. H. Kang, Y. H. Chun, and H. Weh, "Analysis and optimal design oftransverse flux linear motor with PM excitation for railway traction," in Proc. Inst. Elect. Eng., Electr. Power Appl., vol. 150, 2003, pp. 493-499.

[20] R. L. Stoll, The Analysis of Eddy Currents. Oxford, U.K.: Clarendon, 1974.

[21] H. de Pistoyes, "Eddy current losses in the stator ends of machines of large pole pitch and means of reducing these losses," Rev. Gen. Electr., vol. $21,1927$.

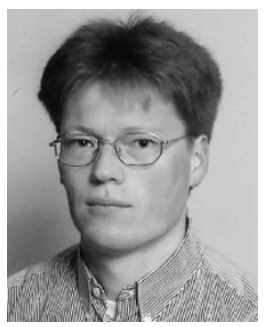

Henk Polinder (M'97) was born in Nunspeet, The Netherlands, in 1968. He received the M.Sc. and $\mathrm{Ph} . \mathrm{D}$. degrees from Delft University of Technology, Delft, The Netherlands, in 1992 and 1998, respectively.

From 1996 to 2003, he was an Assistant Professor and since 2003, he has been an Associate Professor in the Electrical Power Processing Group of Delft University of Technology. In 2002, he spent a few months at the University of Newcastle-upon-Tyne, Newcastle-upon-Tyne, U.K. He is mainly interested in the design aspects of electrical machines for renewable energy and mechatronic applications. 


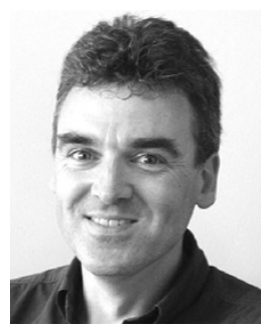

Barrie C. Mecrow (M'98) is a Professor of electrical power engineering with the University of Newcastle-upon-Tyne, Newcastle-upon-Tyne, U.K., where he has been since 1987 . He was a Turbogenerator Design Engineer with NEI Parsons, Newcastle-upon-Tyne, until 1987. He is involved in a range of research projects, including fault-tolerant drives, high-performance permanent-magnet (PM) machines, and novel switched reluctance drives.

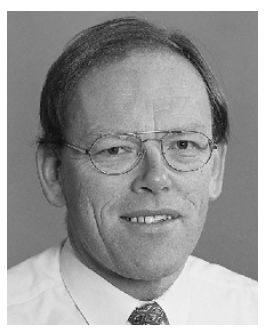

Alan G. Jack (M'00) received the Ph.D. degree for work on numerical analysis of electromagnetic (EM) fields in turbogenerators from Southampton University, Southampton, U.K., in 1975.

$\mathrm{He}$ is past head of the department and leader of the Newcastle Electric Drives and Machines Group at the University of Newcastle-upon-Tyne, Newcastle-upon-Tyne, U.K. He has been with Southampton University for more than 20 years, joining them from NEI Parsons, Newcastle-upon-Tyne, whom he was with for 13 years with roles from Craft Apprentice to Principal Design Engineer. He is the author of more than 80 papers in the area of electrical machines and drives. He holds the Department's Chair in electrical engineering.

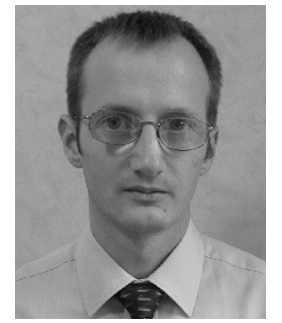

Phillip G. Dickinson received the B.Eng. degree in mechanical engineering and the Ph.D. degree from the University of Newcastle-upon-Tyne, Newcastleupon-Tyne, U.K., in 1989 and 2003, respectively.

$\mathrm{He}$ was a Design Engineer with Rolls-Royce International Research and Development Ltd., Newcastle-upon-Tyne, U.K. He joined the university in 1993 as a Research Associate, working on the mechanical design and analysis of flywheel systems for energy storage. Then, he moved his research focus to the use of soft magnetic composites in electrical machines. Currently, he is a Senior Design Engineer with Switched Reluctance Drives Ltd., Harrogate, U.K.

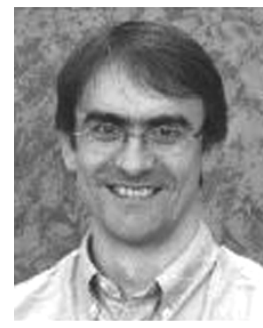

Markus A. Mueller (M'00) received the B.Sc. degree in electrical and electronic engineering from Imperial College, London, U.K., in 1988, and the Ph.D. degree in electrical engineering from the University of Cambridge, Cambridge, U.K., in 1991.

For three years, he was a Research Assistant with Cambridge University, working on induction motors, and then spent two years in industry with Switched Reluctance (SR) Drives Ltd., Harrogate, U.K. Currently, he is a Lecturer in the School of Engineering with the University of Durham, Durham, U.K. In 2004, he moved to a lectureship in the Department of Engineering and Electronics, Institute of Energy Systems, University of Edinburgh, Edinburgh, U.K. His research interests include the design of low-speed electrical machines for direct-drive wind and marine renewable energy converters, finite-element modeling of electrical machines, switched-reluctance (SR) machines, and novel permanent-magnet (PM) machines. 